Programming in Z80 Assembly Language 
Also from Macmillan

Advanced Graphics with the BBC Model B Microcomputer Ian O. Angell and Brian J. Jones

Advanced Graphics with the Sinclair ZX Spectrum

Ian O. Angell and Brian J. Jones

Assembly Language Programming for the Acorn Electron

Ian Birnbaum

Assembly Language Programming for the BBC Microcomputer, second edition

Ian Birnbaum

Advanced Programming for the $16 \mathrm{~K} \mathrm{ZX81}$

Mike Costello

Using Your Home Computer

Garth W.P. Davies

Beginning BASIC

Peter Gosling

Continuing BASIC

Peter Gosling

Practical BASIC Programming

Peter Gosling

Program Your Microcomputer in BASIC

Peter Gosling

Codes for Computers and Microprocessors

P. Gosling and Q. Laarhoven

Microprocessors and Microcomputers - their use and programming Eric Huggins

The Sinclair ZX81 - Programming for Real Applications

Randle Hurley

More Real Applications for the ZX81 and ZX Spectrum

Randle Hurley

Digital Techniques

Noel Morris

Microprocessor and Microcomputer Technology

Noel Morris

The Alien, Numbereater, and Other Programs for Personal

Computers - with notes on how they were written

John Race

Understanding Microprocessors

B.S. Walker

Assembly Language Assembled - for the Sinclair ZX81

Anthony Woods 


\title{
Programming in Z80 Assembly Language
}

\author{
Roger Hutty
}

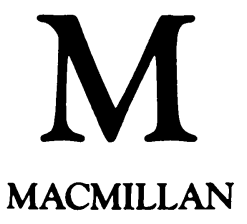


(C) Roger Hutty 1984

\begin{abstract}
All rights reserved. No part of this publication may be reproduced or transmitted, in any form or by any means, without permission.

First published 1984 by Higher and Further Education Division MACMILLAN PUBLISHERS LTD

London and Basingstoke Companies and representatives throughout the world
\end{abstract}




\section{Contents}

$\begin{array}{ll}\text { Preface } & \text { ix }\end{array}$

Chapter 1 The 280 architecture 1

1.1 Microprocessor systems 1

1.2 The $\mathrm{Z} 80$ central processing unit 2

1.3 Memory 3

1.4 Instructions 4

1.5 Assembly language 4

Chapter 2. Accumulator and register instructions 6

2.1 Load A register with a value 6

2.2 Add and subtract a value 6

2.3 Add and subtract a register 7

2.4 Load one register with another 7

2.5 Increment and decrement a register 7

2.6 Negate the accumulator 8

2.7 Addressing modes - immediate and extended 8

2.8 Labels 9

2.9 Program 10

$\begin{array}{lll}\text { Chapter } 3 & \text { Subroutines and display output } & 11\end{array}$

3.1 Subroutine concepts 11

3.2 The CALL and RET instructions 12

3.3 Display output 13

3.4 Pseudo operations 14

3.5 Program 15

Chapter 4 Unconditional jumps and keyboard input 16

4.1 Unconditional jumps 16

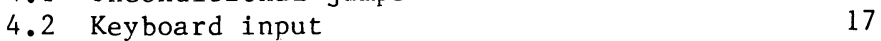

4.3 Character codes and values 18

4.4 The EQU pseudo operator 19

4.5 Program 20

Chapter 5 Flags, conditional jumps and the CP instruction 21

5.1 The flag register 21

5.2 Conditional jump instructions 22

5.3 The compare instruction 23

5.4 Conditional loop termination 24

5.5 Program 25 
Chapter 6 Counting loops and the stack 26

6.1 Counting loops 26

6.2 Number input 28

6.3 The stack 29

6.4 The stack instructions 30

6.5 Saving and restoring registers 30

6.6 Program 31

$\begin{array}{lll}\text { Chapter } 7 & \text { Nested loops and addressing modes } & 33\end{array}$

7.1 Nested loops 33

7.2 Immediate extended and register indirect

7.3 The DEFM pseudo operator 36

7.4 Text output 37

7.5 The subroutine mechanism 37

$\begin{array}{lll}7.6 \text { Program } & 38\end{array}$

$\begin{array}{llll}\text { Chapter } 8 & \text { Carry and overflow } & 40\end{array}$

8.1 Carry 40

8.2 The carry flag 40

8.3 Overflow 41

8.4 The overflow flag 42

8.5 Conditional CALLs and RETs 42

8.6 Program 43

Chapter 9 Bit operations and the index registers 45

9.1 The BIT test instruction 45

9.2 The SET and RES instructions 46

9.3 The DEFS pseudo operator 46

9.4 The index registers 47

9.5 Expressions 47

9.6 Jump tables 48

9.7 Prog ram $\quad 50$

Chapter 10 Shift instructions, multiply and divide 51

10.1 The SRL instruction 51

10.2 The SRA instruction 52

10.3 The SLA instruction 52

10.4 8-bit multiplication and division 53

10.5 Program $\quad 55$

Chapter 11 Logical operations and macros 56

11.1 Logic operators 56

11.2 Logical instructions $\quad 56$

11.3 Masking 57

11.4 Macros 57

11.5 Conditional pseudo operations 60

11.6 Program 62 
12.1 Accumulator rotate instructions

12.2 Register and memory byte rotate instructions 65

12.3 Packing and unpacking

12.4 Parity

12.5 The parity flag

12.6 Program

Chapter 13 16-bit and multiple byte arithmetic

13.1 The DEFW pseudo operator

13.2 The 16-bit ADD, ADC and SBC instructions 70

13.3 Extended loops $\quad 72$

$\begin{array}{ll}13.4 \text { Multiple byte arithmetic } & 74\end{array}$

13.5 Program $\quad 75$

Chapter 14 Block transfer and search instructions 76

14.1 Block transfer instructions 76

14.2 Block search instructions 79

$\begin{array}{ll}14.3 \text { Program } & 81\end{array}$

Chapter 15 Decimal arithmetic 83

15.1 BCD representation 83

15.2 BCD arithmetic 84

15.3 The DAA instruction 86

15.4 The digit rotate instructions 87

$\begin{array}{ll}15.5 \text { Program } & 89\end{array}$

Chapter 16 Miscellaneous instructions 90

16.1 The NOP instruction 90

16.2 The auxiliary registers 90

16.3 Input and output instructions 91

16.4 Interrupt instructions 91

Appendix A Binary and hexadecimal number systems 93

A. 1 Binary and hexadecimal numbers 93

A.2 Binary and hexadecimal arithmetic 95

A.3 Decimal to hexadecimal conversion 95

A.4 Hexadecimal to decimal conversion 95

A.5 Binary-hexadecimal conversion 96

A.6 Decimal-binary conversions 97

A.7 Bytes 97

A.8 Signed (2's complement) numbers 97

Exercise answers $\quad 99$

Appendix B Hexadecimal-decimal conversion tables 101 
Appendix C Summary of Z80 instructions 103

Table C.1 Summary of flag operations 104

Table C.2 8-bit load group 105

Table C.3 16-bit load group 106

Table C. 4 Exchange group and block transfer 107 and search group

Table C.5 8-bit arithmetic and logical group 108

Table C. 6 General purpose arithmetic and CPU control groups 109

Table C.7 16-bit arithmetic group 110

Table C.8 Rotate and shift group 111

Table C. 9 Bit set, reset and test group 112

Table C.10 Jump group 113

Table C.11 Call and return group 114

Table C.12 Input and output group 115

Appendix D Display and keyboard character codes 116

$\begin{array}{lll}\text { Appendix E Expression operators } & 117\end{array}$

$\begin{array}{ll}\text { Index } & 118\end{array}$ 


\section{Preface}

Many microcomputer systems, home and business ones, are based on Zilog's Z80 microprocessor, one of the most commonly used microprocessors.

All microcomputer systems have the facility to run programs written in one or more high-level languages such as BASIC, PASCAL, COBOL, FORTRAN and FORTH. However, sometimes it is necessary (because of speed or memory restrictions) or desirable to run programs written in the assembly language of a microcomputer system. If the microcomputer system is based on a $\mathrm{Z} 80$ microprocessor then the $\mathrm{Z} 80$ assembly language must be used.

This book covers all of the facilities provided by the 280 assembly language, starting with the simple facilities and building on them step-by-step to gradually include the more complex facilities.

Learning a programming language is like learning a foreign language - you need plenty of practical experience. At the end of each chapter there is a practical program for you to do. Programs from some of the chapters are used in later practicals so that you can develop quite substantial programs, relatively easily. The practicals have been carefully chosen to be interesting and visually rewarding - all practicals except the first produce some form of output on the display.

\section{ACKNOWLEDGEMENTS}

My thanks to Leicester Polytechnic for allowing me to use their computer facilities for the development of programs and production of the book, and to Mark Folker for his thorough checking of the text and many suggested improvements. Also, I wish to thank my wife, Susan, for her support in many ways, particularly in the typing of the text using a word processor.

Roger Hutty 